\title{
Mosaico digital de aerofotos não-convencionais na avaliação de recursos naturais: Estudo de caso $^{1}$
}

\author{
Alexson de M. Cunha ${ }^{2}$, João L. Lani ${ }^{3}$, Eufran F. do Amaral ${ }^{2}$, Sérvulo B. de Rezende ${ }^{3}$ \& Luziane dos S. Ribeiro
}

\section{RESUMO}

Pelo presente trabalho avaliou-se a utilização de aerofotos não-convencionais na forma de mosaico digital, como ferramenta básica no levantamento de solos e seu uso. O aerolevantamento foi realizado em quatro microbacias do município de Guarapari, ES. Foram feitas oito faixas de sobrevôos fotográficos com recobrimento longitudinal de $60 \%$ e lateral de $40 \%$. A partir da digitalização de fotografias com elementos no tamanho $9 \times 9 \mathrm{~cm}$ na escala aproximada de 1:25.000, produziu-se um mosaico digital com o auxílio do software Visual Stitcher. Os mapas de solos e de uso da terra foram delineados sobre o mosaico georreferenciado, com a utilização de digitalização em tela do software Idrisi 32. O uso do mosaico digital facilitou e agilizou o processo de mapeamento dos solos e da delimitação do uso da terra na área estudada.

Palavras-chave: fotointerpretação, geoprocessamento, uso da terra, fotopedologia

\section{Digital mosaic of non-conventional aerial photographs in the evaluation of natural resources: Case study}

\begin{abstract}
The present work evaluated the use of non-conventional aerial photographs in digital mosaic format as a basic tool for soils and land use surveys. The aerial survey was accomplished over small basins from Guarapari, Espírito Santo State, Brazil. Eight flight lines were made with $60 \%$ of longitudinal overlap and $40 \%$ of lateral overlap. The digital mosaic was produced with the software Visual Stitcher starting from the digitizing of photographic elements in $9 \times 9 \mathrm{~cm}$ size in the approximate scale of 1:25,000. The soils and land use maps were delineated on the geo-referenced mosaic by on-screen digitizing tool of Idrisi 32. The use of digital mosaic facilitated and speeded up the soil and land use surveys.
\end{abstract}

Key words: photointerpretation, geoprocessing, land use, photopedology

1 Parte da Dissertação de Mestrado do primeiro autor, apresentada à UFV, Viçosa, MG.

2 Pós-graduando, UFV. CEP 36.571-000 - Viçosa, MG. Fone: (31) 3899-2894. E-mail: alexsonc@yahoo.com.br

${ }^{3}$ Departamento de Solos/UFV. CEP 36.571-000 - Viçosa, MG. Fone: (31) 3899-2894. E-mail: lani@ufv.br

${ }^{4}$ Pós-graduanda, UENF. CEP 28.015-620 - Campos dos Goytacazes, RJ. E-mail: neput@ufv.br 


\section{INTRODUÇÃO}

As aerofotos não-convencionais, também conhecidas como de "pequeno formato", são uma ótima ferramenta para o levantamento de informações detalhadas, de grande importância no planejamento do uso dos recursos naturais; são assim denominadas porque: a) não são obtidas com câmaras métricas, tendo em vista serem extremamente dispendiosas e inviabilizam, pelo seu custo, o acesso de pequenas instituições ou empresas; b) são ampliadas, e c) não têm marcas fiduciais (Disperati, 1991).

As imagens de satélite utilizadas em estudos de solo, oferecem uma visão geral mas não permitem o detalhamento, quando necessário. As aerofotos convencionais são de extrema utilidade na fotogrametria e fotointerpretação, porém este tipo de aerolevantamento é de elevado custo, inibindo com freqüência o seu uso (Disperati, 1998). As aerofotos não-convencionais são de baixo custo e, portanto, mais acessíveis aos interessados em estudos mais detalhados de pequenas áreas. São fotografias coloridas, permitem visão tridimensional que facilitam a interpretação e o mapeamento necessário ao planejamento territorial, tanto no meio rural quanto no meio urbano, como em loteamentos, base para cálculo do IPTU e outros fins.

Os mosaicos de aerofotos são particularmente úteis para o planejamento e monitoramento de áreas de preservação, diagnóstico do crescimento urbano e análise dos recursos naturais (Marchetti \& Garcia, 1977); são, conforme o método tradicional, imagens geradas da concatenação de fragmentos de aerofotos em papel, recortadas e sistematicamente coladas, com o propósito de formar uma imagem global da área fotografada. Ultimamente tem-se estudado a confecção de mosaicos feitos a partir de aerofotos digitalizadas (Elmiro, 1994).

Como alternativa aos métodos cartográficos tradicionais, as aerofotos digitais ortofotizadas, na forma de "fotomapas digitais", têm sido também sugeridas como ferramenta para atualizações cartográficas (Raffo \& Menezes, 1996).

Estudos de quantificação e distribuição espacial do uso da terra e tentativa de delineamentos semidetalhados de solos, usando-se aerofotos não-convencionais, foram desenvolvidos por Fernandes (1996), Quinteiro (1997). Nos dois casos, a interpretação das aerofotos seguiu o método tradicional, através de estereoscópio de espelho e delimitação das diferentes unidades com posterior transferência dos dados interpretados para o mapa-base, compilado de cartas topográficas. Nesse estudo, Fernandes (1996) concluiu que as aerofotos na escala aproximada de 1:5.000 permitiram um fácil mapeamento de unidades pedológicas da paisagem; entretanto, não obteve o mesmo resultado utilizando escalas menores.

Quinteiro (1997), empregando aerofotos na escala aproximada de 1:15.000, deduziu que as aerofotos apresentaram boa nitidez e estereoscopia para mapear os diversos usos da terra, porém nessa escala houve dificuldades para mapear ambientes e separar as classes de solo em áreas de relevos acidentados.

O presente trabalho foi realizado com o objetivo de estudar o uso da terra e o mapeamento dos solos de uma micro- bacia do município de Guarapari, ES, com base em aerofotos não-convencionais e de gerar uma metodologia específica de confecção de mosaico digital semicontrolado para a sua utilização como ferramenta básica na avaliação de recursos naturais.

\section{MATERIAL E MÉTODOS}

A área do presente estudo corresponde à microbacia do Córrego do Oratório, município de Guarapari, Espírito Santo; entretanto, para a confecção do mosaico utilizaram-se as aerofotos obtidas no levantamento aerofotográfico correspondente à área de quatro microbacias (Figura 1). As fotografias aéreas não-convencionais foram obtidas segundo processo desenvolvido por Rezende et al. (1986). O aerolevantamento foi realizado pelo Núcleo de Estudos de Planejamento e Uso da Terra (NEPUT) da Universidade Federal de Viçosa, MG, em 10/10/2002. Como plataforma aérea utilizou-se uma aeronave CESSNA 182-Skylane, com uma câmera Hasselblad - modelo 553 ELX, munida de objetiva Zeiss Distagon de $50 \mathrm{~mm}$. No plano de sobrevôo usou-se um GPS Garmin 195 map e o programa GPS TrackMaker versão 11.7 (Ferreira Junior, 2004). Foram feitas oito faixas de vôos fotográficos (recobrimento longitudinal de $60 \%$ e lateral de $40 \%$ e altura de vôo de $2.000 \mathrm{~m}$ acima do plano de referência de $300 \mathrm{~m}$ de altitude). Obteve-se o total de 136 aerofotos, que cobriram as áreas das quatro microbacias (aproximadamente $13.000 \mathrm{ha}$ ).

Os principais tipos de solo da microbacia em estudo foram caracterizados por Cunha (2003), cujas classes de solo foram definidas com observações a campo e laboratoriais, em conformidade com as normas, critérios e nomenclatura adotados por EMBRAPA (1999). Em cada perfil foi realizada a descrição morfológica (Lemos \& Santos, 1996) e coletadas amostras de solo em cada horizonte e analisadas segundo EMBRAPA (1997).

As classes de solos foram reconhecidas no mosaico a partir da visualização das pedoformas (morfologia externa do solo) em três dimensões nas aerofotos com escala aproximada de 1:10.000, utilizando-se de um estereoscópio de espelho (Zeiss).

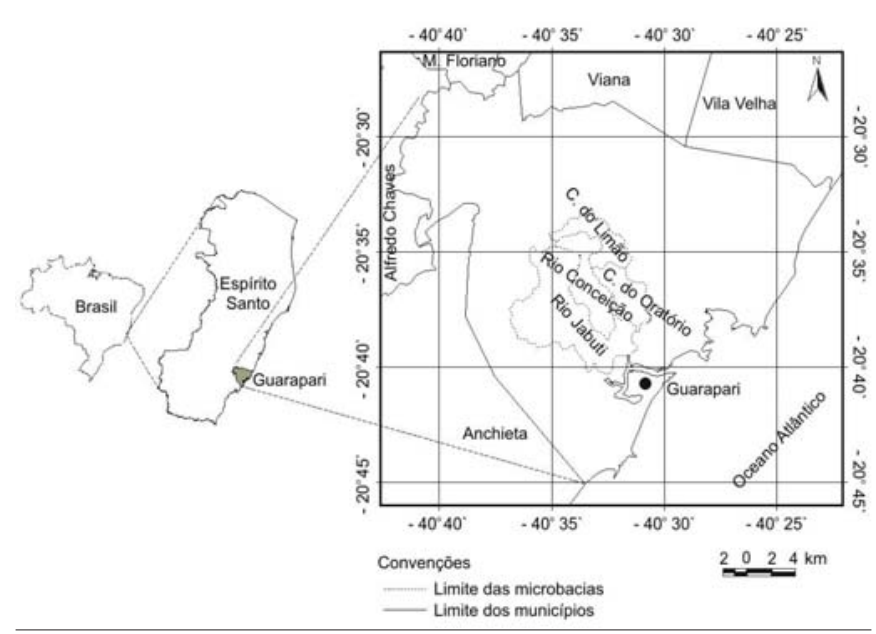

Figura 1. Localização da área de estudo, no Estado do Espírito Santo. 


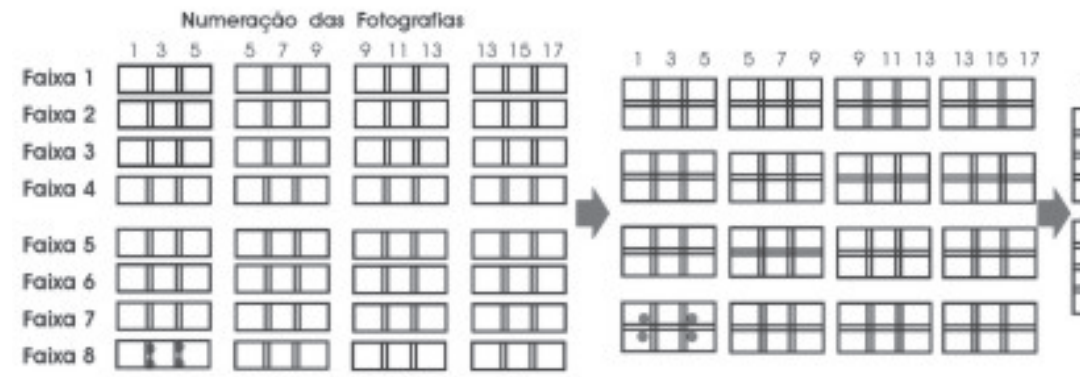

Etapa 1

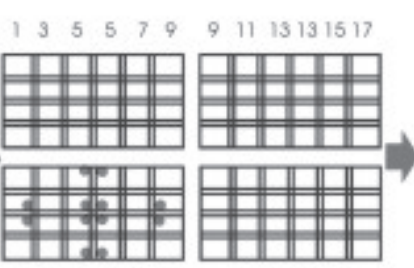

Etapa 3

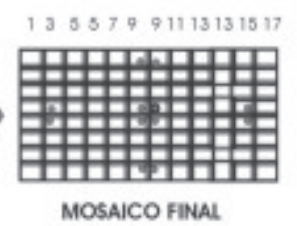

Etapa 4

Figura 2. Esquema de montagem das aerofotos não-convencionais para elaboração do mosaico.

O uso da terra foi obtido a partir das análises de elementos de fotointerpretação, tais como: textura, cor, forma, tamanho, localização e posição no relevo, que permitiram a individualização de polígonos homogêneos, quanto aos diferentes usos presentes na área de estudo.

\section{RESULTADOS E DISCUSSÃO}

Inicialmente, produziu-se um fotoíndice das faixas de aerofotos usadas, através de um processo fotográfico comumente conhecido por "copião". As aerofotos ampliadas e copiadas em papel no tamanho de 9 x $9 \mathrm{~cm}$ (escala nominal aproximada de 1:25.000) foram então digitalizadas com resolução de 400 dpi, em scanner Hewlett-Packard Scanjet 5.300C. Após digitalização em scanner, utilizou-se o programa Visual Stitcher (versão 2.0) (Panavue Inc., 2004) para a importação dos arquivos no formato bmp e geração do mosaico, opcionalmente sem ajuste de cores e com uma sobreposição de imagem com $40 \%$ de "blending" (passagem progressiva de uma foto digital para outra, quando sobrepostas). A fim de diminuir a sobreposição de área das fotografias dentro das faixas, preferiu-se o uso das aerofotos de numeração ímpar. Entre as faixas, as aerofotos digitalizadas foram editadas no programa Corel Photopaint 10 (Corel Corporation, 2004), procurando-se eliminar as bordas.

O mosaico final foi obtido em quatro etapas, nas quais foram utilizadas 64 aerofotos diferentes (Figura 2); na primeira etapa e em cada faixa, obtiveram-se quatro mosaicos constituídos por três aerofotos para cada mosaico, os quais, na segunda etapa, foram unidos de modo a se obter mosaicos com seis aerofotos. Para facilitar a composição dos mosaicos nas etapas 3 e 4, as aerofotos de números 5, 9 e 13 foram utilizadas repetidamente nos mosaicos subseqüentes, dentro de cada faixa; nas terceira e quarta etapas, os mosaicos foram montados, respectivamente, com o uso de 24 e 96 aerofotos. Nesta última fase, a junção dos mosaicos foi mais complexa devido, provavelmente, a diferentes escalas nas aerofotos em razão de diferentes altitudes relacionadas com o relevo acidentado da área. Conforme Rezende Filho (2001), variações na altitude e deriva da aeronave são fatores que ocasionam problemas na junção das aerofotos. Para contornar este problema, os pontos coincidentes entre aerofotos foram escolhidos tentativamente, até que se produzisse um mosaico coerente.
Utilizou-se o sistema de informações geográficas Idrisi 32 (Easteman, 1999), para o georreferenciamento do mosaico (Figura 3) e obtenção dos mapas temáticos de solos e uso atual da microbacia do Córrego do Oratório e, para georreferenciamento, o módulo "RESAMPLE" do software Idrisi 32, com função quadrática, cujas coordenadas do sistema Universal Transverse Mercator (UTM) foram obtidas a partir de locais de fácil localização na carta topográfica editada pelo Instituto Brasileiro de Geografia e Estatística (IBGE), Folha Alfredo Chaves (SF - $24-\mathrm{V}-\mathrm{A}-\mathrm{VI}-2$ ).

Os limites e a área da microbacia foram delineados com o auxílio da carta topográfica do IBGE e das aerofotos nãoconvencionais, e o delineamento dos solos e do uso atual foi realizado sobre o mosaico georreferenciado utilizando-se digitalização em tela do software Idrisi 32. Os mapas foram

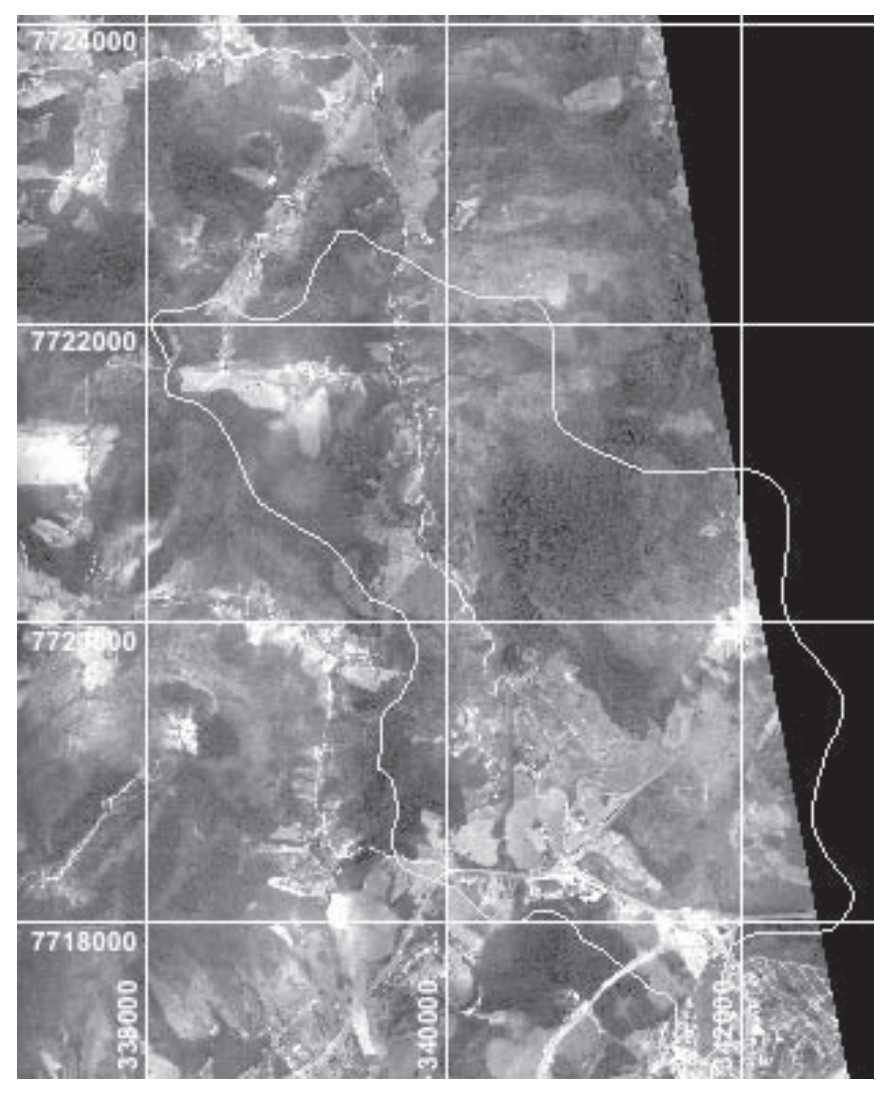

Figura 3. Mosaico semicontrolado da microbacia do Córrego do Oratório - Guarapari, ES. 

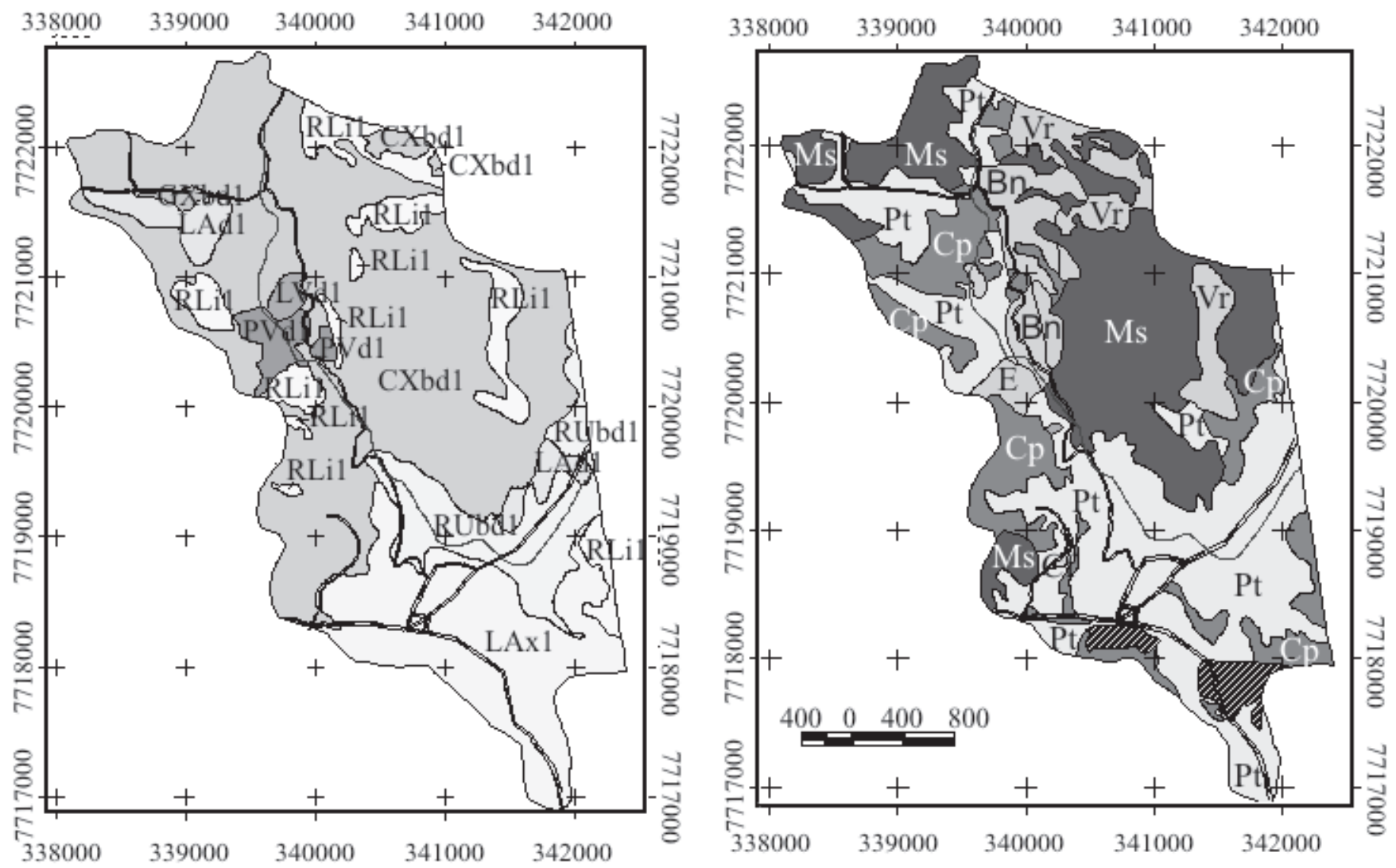

LEGENDA

$\square$ PVd1 ARGISSOLO VERMELHO Distrófico típico, relevo suave e ondulado

RLi1 Associação NEOSSOLO LITÓLICO Hístico típico,

+ Afloramento de Rochas, relevo montanhoso e escarpado

CXbd1 Associação CAMBISSOLO HÁPLICO Tb Distrófico típico + CAMBISSOLO HÁPLICO Tb Distrófico latossólico, relevo montanhoso e forte ondulado

GXbd1 GLEISSOLO HÁPLICO Tb Distrófico típico, relevo plano

LAd1 LATOSSOLO AMARELO Distrófico típico, relevo forte ondulado e montanhoso

LAx1 LATOSSOLO AMARELO Coeso típico, relevo ondulado e suave ondulado

LVd1 LATOSSOLO VERMELHO Distrófico típico, relevo forte e ondulado

LEGENDA

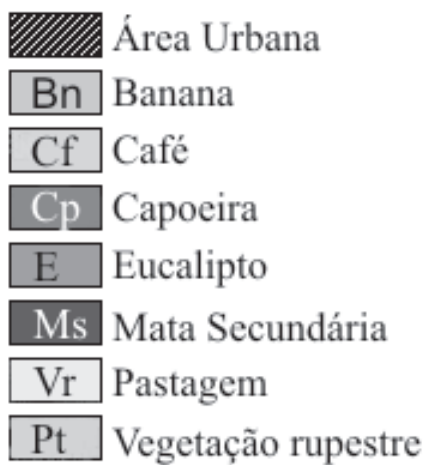

Convenções cartográficas

— Estrada com pavimento

— Estrada sem pavimento

RUbd NEOSSOLO FLÚVICO Tb Distrófico gleico, relevo plano

Figura 4. Mapas de solo e de uso da terra da microbacia do Córrego do Oratório - Guarapari, ES.

redigitalizados no programa Arc Info (ESRI, 2004b) e, posteriormente, exportados no formato "shape" para obtenção do layout final no software ArcView GIS 3.2a (ESRI, 2004a).

Utilizando-se a opção "ajuste de cores" do Visual Stitcher, obteve-se o melhor resultado na primeira etapa, quando os mosaicos se compuseram apenas de três fotografias. Para mosaicos com maior número de fotografias obtiveram-se melhores resultados sem a função "ajuste de cores". Melho- res resultados também foram obtidos utilizando-se a menor área de sobreposição entre fotografias de uma mesma faixa e entre faixas de sobrevôo. O aumento da sobreposição produzia imagens duplicadas no mosaico.

Apesar do Visual Stitcher não ser um programa específico para aerofotos, mostrou-se eficiente para tal finalidade, mas foi necessário o seu georreferenciamento no Idrisi 32, na tentativa de corrigir as distorções causadas durante a 
Tabela 1. Áreas ocupadas pelas classes de solo na microbacia do Córrego do Oratório

\begin{tabular}{|c|c|c|c|}
\hline \multirow{2}{*}{ Classes } & \multirow{2}{*}{ Simbologia } & \multicolumn{2}{|c|}{ Área } \\
\hline & & (ha) & $(\%)$ \\
\hline $\begin{array}{l}\text { Associação Cambissolo Háplico Tb } \\
\text { Distrófico típico + Cambissolo Háplico Tb } \\
\text { Distrófico latossólico }\end{array}$ & CXbd1 & 665,1 & 55,9 \\
\hline Gleissolo Háplico Tb Distrófico típico & GXbd1 & 4,8 & 0,4 \\
\hline Latossolo Amarelo Distrófico típico & LAd1 & 27,8 & 2,3 \\
\hline $\begin{array}{l}\text { Associação Latossolo Amarelo Coeso } \\
\text { típico + Argissolo Amarelo Distrófico } \\
\text { típico (Barreiras) }\end{array}$ & Lax1 & 242,1 & 20,3 \\
\hline Latossolo Vermelho Distrófico típico & LVd1 & 7,57 & 0,6 \\
\hline Argissolo Amarelo Distrófico típico & PVd1 & 24,2 & 2,0 \\
\hline $\begin{array}{l}\text { Associação Neossolo Litólico Hístico típico } \\
+ \text { afloramento de rocha }\end{array}$ & RLi1 & 106,4 & 8,9 \\
\hline Neossolo Flúvico Tb Distrófico gleico & RUbd1 & 112,2 & 9,4 \\
\hline Total & & $1.190,2$ & 100,0 \\
\hline
\end{tabular}

mosaicagem e fornecer coordenadas reais, de maneira que, conforme Rezende Filho (2001), pudesse ser utilizado como ferramenta cartográfica eficaz.

Utilizando-se o mosaico e as aerofotos não-convencionais, foi possível mapear as principais classes de solo e de uso da terra (Figura 4). Conforme se observa na Tabela 1, a unidade de mapeamento de solo de maior ocorrência foi CXbd1 (Cambissolos), seguida de LAx1 (Latossolos). Os Cambissolos, de pequena profundidade efetiva, ocorrem em área bem dissecada, formando vale em formato de "V", com encostas de alta declividade, tornando a área sujeita à instabilidade, do ponto de vista ambiental.

As unidades de uso "mata secundária" e "capoeira", ocupam a maior área da microbacia (Tabela 2), ocupando, em geral, as encostas declivosas e topos, coincidindo a maior parte com as áreas de Cambissolos. As pastagens para criação de gado ocupam maior área $(39,5 \%)$, ocorrendo principalmente sobre os Latossolos Amarelos coesos e Argissolos Amarelos do tabuleiro costeiro.

No presente estudo, as aerofotos não-convencionais na escala aproximada 1:10.000 apresentaram boa nitidez e estereoscopia, o que facilitou a identificação das classes de solo e de uso agrícola.

O uso do mosaico digital na escala aproximada de

Tabela 2. Uso da terra na microbacia do Córrego do Oratório

\begin{tabular}{lcc}
\hline \multirow{2}{*}{ Classes } & \multicolumn{2}{c}{ Área } \\
\cline { 2 - 3 } Mata secundária & (ha) & (\%) \\
Capoeira & 339,9 & 28,6 \\
Vegetação rupestre & 192,5 & 16,2 \\
Banana & 96,8 & 8,1 \\
Café & 60,1 & 5,1 \\
Pastagem & 2,1 & 2,1 \\
\hline Eucalipto & 470,2 & 39,5 \\
Área urbana & 0,9 & 0,1 \\
Total & 28,0 & 2,4 \\
\hline
\end{tabular}

1:25.000, subsidiou a fotointerpretação, permitiu uma visão de conjunto e maior facilidade de delineamento das classes de uso da terra e dos solos (Figura 4) e, também, a quantificação dessas classes (Tabelas 1 e 2).

\section{CONCLUSÕES}

1. O uso de aerofotos não-convencionais de baixo custo na forma de mosaico digital mostrou-se eficiente, facilitando e agilizando o processo de levantamento dos solos e do uso da terra, especialmente no planejamento de pequenas bacias hidrográficas, como no caso presente, e se apresenta com potencial para estudos em áreas urbanas.

2. O mosaico digital mostrou-se promissor em razão da possibilidade de se obter escalas que oferecem um bom nível de detalhamento das classes de solos e de uso atual estudadas.

3. As aerofotos não-convencionais apresentaram excelente efeito estereoscópico e nitidez, o que facilitou a identificação das classes de solos e seu uso.

4. O uso de mosaicos georrefereciados produzidos a partir de aerofotos digitalizadas possibilita a ampliação do uso das aerofotos para uma visão de conjunto da área de estudo.

5. As principais classes de solo da microbacia Córrego do Oratório, foram os Cambissolos Háplicos, que ocorrem na área acidentada e os Latossolos Amarelos coesos dos tabuleiros costeiros.

6. As classes de uso de maior expressividade em área ocupada na microbacia Córrego do Oratório, foram mata secundária, capoeira e pastagem.

\section{LITERATURA CITADA}

Corel Corporation. Corel Draw 10. http://www.corel.com. 06 Jun. 2004.

Cunha, A. M. Ambientes, solos e uso com vistas ao potencial de produção de água em microbacias (Mata Atlântica) do município de Guarapari, ES. Viçosa: UFV, 2003. 134p. Dissertação Mestrado

Disperati, A. A. Obtenção e uso de fotografias aéreas de pequeno formato. Curitiba: UFPR/FUPEF, 1991. 290p.

Disperati, A. A. Fotografias aéreas de pequeno formato para recuperação de áreas degradadas. In: Dias, L. E., Mello, J. W. V. de. (ed.) Recuperação de áreas degradadas. Viçosa: UFV/SOBRADE, 1998. p.87-94.

Easteman, J. R. Idrisi 32. Worcester: Clark University, 1999. 1 CD-ROM.

Elmiro, M. A. T. Técnicas de processamento digital de imagens para aplicações no mapeamento por carta-imagem. São José dos Campos: INPE, 1994. 130p.

EMBRAPA - Empresa Brasileira de Pesquisa Agropecuária. Centro Nacional de Pesquisa de Solos. Manual de métodos de análise de solo. 2.ed. Rio de Janeiro: Embrapa Solos, 1997. 212p.

EMBRAPA - Empresa Brasileira de Pesquisa Agropecuária. Centro Nacional de Pesquisa de Solos. Sistema brasileiro de classificação de solos. Rio de Janeiro: Embrapa Solos, 1999. 412p. 
ESRI - Environmental Systems Research Institute, Arc View GIS 3.2a. http:// www.esri.com/software/arcview.15 Jun. 2004a.

ESRI - Environmental Systems Research Institute, Arc Info 8.0.1. http:// www.esri.com/software/arcinfo/index.html.15 Jun. $2004 b$.

Fernandes, M. M. Caracterização de solos e uso atual empregando-se aerofotos nãoconvencionais nas sub-bacias Marengo, Palmital e Silibar-Rio Turvo Sujo, MG. Viçosa:UFV, 1996. 107p. Dissertação Mestrado

Ferreira Junior, O. GPS Trackmaker 11.7. http:/gpstm.com/eng/features_eng.htm. 06 Jun. 2004.

Lemos, R. C. de; Santos, R. D. dos. Manual de descrição e coleta de solo no campo. 3.ed. Campinas. SBCS/CNPS, 1996. 83p.

Marchetti, D. A. B.; Garcia, G.J. Princípios de fotogrametria e fotointerpretação. São Paulo: Nobel, 1977.257p.
Panavue Inc. Visual Stitcher 2.0. http://www.panavue.com/downloads/index.htm. 06 Jun. 2004.

Quinteiro, F. Q. L. Levantamento do uso da terra e caracterização de ambiente da Bacia Hidrográfica do Rio Turvo Sujo com a utilização de aerofotos não-convencionais. Viçosa: UFV, 1997. 91p. Dissertação Mestrado

Raffo, J. G.; Menezes, J. C. Fotomapa digital. In: Congresso Nacional de Engenharia de Agrimensura. 7. 1996, Salvador. Anais... http://geodesia.ufsc.br/geodesiaonline/ar-quivo/conea7/520.pdf: 15 jun. 2004.

Rezende, S. B.; Ribeiro, J. C.; Silva, T. C. A.; Resende, M.; Costa, L. M.; Aspiazú, C.; Soares, V.P.; Ribeiro, G. A. Levantamento de solo e uso atual, erosão e cobertura vegetal de três microbacias, no vale do Rio Turvo Sujo, com a utilização de aerofotos não-convencionais. Viçosa:UFV, 1986. 13p. Projeto dePesquisa

Rezende Filho, F. V. de. Mosaico digital semicontrolado obtido de aerofotos coloridas não-métricas. Belo Horizonte: UFMG, 2001.37p. Monografia Especialização 